\title{
O papel do CITS' na política de desenvolvimento tecnológico no Paraná
}

\author{
Walter Tadahiro Shimajv \\ Universidade Federal do Paraná \\ Antonio Guilherme de Arruda Lorenzi \\ CITS - Centro Internacional de Tecnologia de Software
}

\begin{abstract}
Resumo
Analisam-se as implicações da produção de software no Paraná. Como produção de bem intangível, há contribuições para a expansão do Sistema Setorial de Inovação. O foco da análise é o Centro Internacional de Tecnologia de Software e sua trajetória natural em direção à capacitação para a inovação radical de forma híbrida. Discute-se a integração entre os conceitos de Sistema Nacional de Inovação e Triple Helix (TH) e apresenta-se sua evolução no Brasil e no Paraná (Sistema Local). O software é a pura expressão do atual paradigma tecnológico. É necessária uma forte política de desenvolvimento centrada nas tecnologias de informação, em função do papel revolucionário exercido nas economias centrais. O CITS se encaixa perfeitamente nessa nova dinâmica, estabelecendo uma estratégia clara de aquisição de competências e construindo uma rede de conhecimento nos níveis micro, meso e macroeconômico. A evolução da fase atual do CITS implicará uma forte ação da TH.
\end{abstract}

Palavras-chave

Conhecimento, Software, Sistema local de inovação, Triple Helix, CITS.

\section{The role of CITS on the policy on technological development in Paraná state}

\begin{abstract}
This article analyses the implications of the software production in Parana state, which strongly contributes to the expansion of the Sectoral Innovation System. The focus is on CITS - Centro Internacional de Tecnologia de Software [International Centre of Software Technology) and its natural trajectory towards the capability for a radical innovation in a hybrid way. It discusses the integration between the concepts of the National System of Innovation and the Triple Helix (TH) and presents its evolution in Brazil, more specifically in Paraná State (Local System). As a pure expression of the current technological paradigm, the software implies a strong policy on development centred on the generic information technologies because of the revolutionary role that such technologies have exercised on central economies. CITS perfectly fits this new dynamics, establishing a clear strategy for acquisition of competencies and building a network of knowledge at the micro-economic, meso-economic, and macro-economic levels. The evolution of the current phase of CITS is going to imply a strong action from TH.
\end{abstract}

Key words

Knowledge, Software, Local system of innovation, Triple Helix, CITS. 


\section{INTRODUĈ̣̃O}

O objetivo principal desse artigo é analisar as implicações do processo de produção de software no Paraná. Verificar-se-á como a produção desse bem intangível contribui para a expansão do Sistema Setorial de Inovação (SSI). A análise será feita levando em conta a evolução do CITS em Curitiba e sua trajetória natural em direção à capacitação para a inovação radical dentro do contexto da evolução do Sistema Nacional de Inovação (SNI). O SNI pode ser caracterizado como uma rede de instituições públicas e privadas cujas atividades e interações absorvem, importam, mudam e difundem novas tecnologias. Esse sistema compreende três níveis de análise: o microeconômico, que abrange a firma, é visto como repositório de conhecimento incorporado no nível das rotinas operacionais e é modificado de tempos em tempos por meio de altos níveis de regras de comportamento e estratégias; o mesoeconômico se refere a uma rede de ligações entre firmas e outras organizações; e o nível macroeconômico está associado a um conjunto de relacionamentos sociais, regras e restrições políticas em que o comportamento microeconômico está embutido (Cimoli \& Della Giusta, 1999:33). Esse é um conceito que tem como premissa as diversas ligações entre os atores envolvidos no processo de inovação, que são chaves para um melhor desempenho tecnológico. A inovação e o desenvolvimento tecnológico são resultados de um conjunto complexo de relacionamentos entre atores do sistema, entidades privadas, universidades e governo, que produzem, distribuem e aplicam vários tipos de conhecimento (OECD, 1997).

Uma evolução importante do conceito de SNI está no conceito da Triple Helix (TH). Esse conceito permite o entendimento da trajetória do CITS numa perspectiva evolucionária. De acordo com Etzkowitz \& Leydesdorff (2000), TH pressupõe que a evolução dos sistemas de inovação, em última instância, deve ser vista como variações dos arranjos institucionais entre universidade, indústria e governo.

A primeira configuração da TH é a TH I. Nessa relação tri-dimensional o estado engloba a universidade e a indústria e conduz as relações entre os dois. A inovação tem um caráter mais normativo, determinado pelo estado e menos pela própria dinâmica da relação universidadeindústria.

A segunda é a TH II, em que o Estado reduz significativamente sua relevância em determinar a direção dos processos inovativos. Trata-se de uma redução do papel do estado numa perspectiva liberalizante e não na direção de o estado assumir um papel dinâmico e interativo com a indústria e a universidade. $\mathrm{O}$ estado reduz seu papel sem que, necessariamente, as outras duas instâncias tenham conseguido alguma dinâmica autônoma e interativa para o processo de inovação. Não significa redução das atividades inovativas, mas uma situação de necessidade de buscar um novo arranjo institucional que envolva o estado numa outra dinâmica. Nesse sentido, o processo de busca e interação numa dinâmica frágil evolui para TH III. É essa nova configuração que justifica o uso desse instrumental analítico para a análise do CITS. A TH III se refere a uma infra-estrutura de conhecimento em que as instâncias envolvidas se sobrepõem e originam organizações híbridas onde todas assumem as mesmas funções relativas à inovação. Não há determinação de uma(s) sobre outra(s) e a inovação, portanto, surge de uma dinâmica interativa. A visão é de que na TH III os processos inovativos se intensificam por conta das amplas possibilidades de spin-off entre os agentes, dado que o foco da relação é o estabelecimento de uma economia de rede que, num sentido mais geral, implica alianças estratégicas, joint-ventures, contratos de parcerias, etc. entre laboratórios, firmas (grandes e pequenas), institutos de pesquisa, universidades e entre todas as instituições ligadas a P\&D. Essa formação de rede é amplamente necessária e possível em função de que a inovação recente implica complexidade. Desse modo, a expectativa é de que a dinâmica interativa entre os agentes seja intensa e, conseqüentemente, não-estacionária. Ou seja, a dinâmica interativa, num determinado ambiente, pode levar aos mais diversos arranjos institucionais, inéditos, em transição permanente.

Tendo a noção integrada de SNI e TH, é possível situar a inovação no Brasil. De acordo com Dahlman \& Frischtak (1993), o SNI brasileiro foi construído durante quatro períodos diferentes:

1. Da colonização até o início do século 20 (1500-1900);

2. A fundação das bases para o crescimento industrial (1900-1946);

3. A industrialização pesada e o início do enfoque preliminar em ciência e tecnologia (1947-1964) e;

4. O período militar e a formalização da infra-estrutura de ciência e tecnologia (1964-1985).

É possível adicionar um quinto período à classificação de Dahlman \& Frischtak (1993). Refere-se ao projeto político/econômico do governo do presidente Fernando Henrique Cardoso, que foi exatamente o oposto dos quatro anteriores. Nesse quinto período, o arranjo setorial/nacional foi desmontado em função do arranjo institucional ao nível macro (1994-2002). Em outros termos, a trajetória natural do SNI brasileiro foi quebrada e o novo arranjo institucional em todas as áreas da economia implicou a redução significativa do papel do estado como 
agente relevante e ativo na determinação das políticas setoriais e das estratégias tecnológicas. O Estado, de tradicional agente ativo do desenvolvimento científico e tecnológico, ao reduzir sua importante atuação, privatizou ativos estatais da infra-estrutura, chaves do desenvolvimento econômico brasileiro (como telecomunicações ${ }^{2}$, buscar mais uma lógica de ajuste fiscal e a funcionar como agente regulador da atividade econômica.

Dentro desse novo ambiente institucional, em 1992, instalou-se em Curitiba o CITS, cujo objetivo central é a promoção da tecnologia de software no Brasil.

$\mathrm{Na}$ seqüência é apresentada a metodologia da pesquisa e, logo, a evolução do SNI e do Sistema Local de Inovação (SLI) para fundamentar a afirmação de que ao longo do tempo, no Paraná, criaram-se as condições adequadas para a implantação de um empreendimento fundamentado numa perspectiva TH III. Verificar-se-á, na sequiência, quais são as relações institucionais estabelecidas pelo CITS que permitem localizá-lo dentro de uma rede dinâmica de inovação - apesar de os agentes precisarem aumentar o grau de interação -, com uma trajetória original em direção a inovações radicais. rodovias, distribuição de energia elétrica, etc.), e passou a

inserir dentro dele e, na sua evolução, consegue formar sua rede de aquisição de competências nos níveis micro, meso e macroeconômico?

2. Por que motivos essa é uma instituição importante a ser estudada dentro do atual paradigma tecnológico (Dosi, 1982)?

3. Que eventuais ações poderiam ser implementadas visando uma elevação das competências do CITS em direção a uma trajetória de inovações radicais/originais?

A construção do artigo teve como fonte documentos oficiais da instituição e observação direta por parte dos autores. A fundamentação teórica não segue uma orientação rígida em termos de expô-la numa seção específica, em separado, e sim é discutida na medida da evolução do texto e da exposição dos elementos relevantes. Notar-se-á que, entrelaçadas aos diversos aspectos discutidos, há afirmações de natureza mais teórica.

\section{As Bases Iniciais do SNI Brasileiro e do SLI no Paraná}

Considerando a classificação de Dahlman \& Frischtak (1993), é possível discutir a construção de um verdadeiro SNI brasileiro a partir do terceiro período. O

Plano de Metas do Presidente Kubitschek (1956-1961) foi o esforço mais ambicioso e organizado em direção à industrialização pesada. No início dos anos 1950, o governo brasileiro encarregou-se do primeiro esforço, de extensão nacional, para a promoção da pesquisa em todas as áreas do conhecimento pela criação do Conselho Nacional de Desenvolvimento Cientifico e Tecnológico (CNPq).

\section{A Metodologia da Pesquisa}

Este artigo usa o estudo de caso como método principal. Isto em função de que experiências similares ao CITS como instituição de pesquisa híbrida são bastante recentes na conformação do SNI brasileiro e, portanto, apresenta elementos relevantes a serem considerados em termos de políticas públicas, numa nova organização institucional da P\&D do País. Trata-se de um tipo de instituição privada de pesquisa, sem fins lucrativos, que atua como suporte às estratégias competitivas e tecnológicas das suas empresas mantenedoras. Isso é diferente do que historicamente ocorreu na evolução do SNI brasileiro, organizado nos moldes TH II. Em outros termos, trata-se de uma nova forma institucional que se relaciona à dinâmica do Estado no quinto período exposto anteriormente.

$\mathrm{O}$ artigo busca responder a algumas questões mais gerais relevantes:

1. Considerando a dinâmica TH III, de que forma o CITS, como uma instituição privada de pesquisa, passa a se
Em 1968-1969, o Plano Estratégico de Desenvolvimento (PED) do governo militar propôs uma política explícita de ciência e tecnologia ao nível federal com o Sistema Nacional de Desenvolvimento Científico e Tecnológico (SNDCT). Nesse sistema, três Planos Básicos de Desenvolvimento Científico e Tecnológico foram criados: PBDCT I, II e III de 1973 a 1985. Muitas outras instituições públicas e programas relacionados a P\&D em diferentes áreas podem ser numerados dentro do II PBDCT e do II Plano Nacional de Desenvolvimento (II PND). O objetivo principal do II PND foi concluir o processo de substituição de importações e aumentar a independência da economia brasileira.

Enquanto a economia brasileira seguia a trajetória de crescimento industrial do $2^{\circ}$ e $3^{\circ}$ períodos da classificação de Dahlman \& Frischtak (1993), a economia do Paraná sustentava-se fundamentalmente nas atividades agropecuárias. É somente no âmbito do II PND que se instalam na Região Metropolitana de Curitiba diversas 
plantas industriais relevantes dentro do paradigma tecnológico vigente naquele momento. São plantas da indústria metalúrgica, mecânica, química e petroquímica. A partir desse período, inicia-se a mudança da estrutura produtiva do Estado do Paraná, que começa a ser visto como uma alternativa de localização industrial concentrada na região da Grande São Paulo (PASSOS, 1998).

Assim, se até o início dos anos 70 o Estado era eminentemente rural, é evidente que as eventuais atividades de P\&D que nele se implantaram ao longo do tempo relacionavam-se à agropecuária. Em 1918, instala-se em Ponta Grossa a primeira unidade de pesquisa agropecuária do Estado (Estação Experimental do Trigo, atual Iapar) e, em Curitiba, cria-se a Escola de Agronomia e Veterinária da antiga Universidade do Paraná. Em 1942, cria-se o Instituto de Biologia e Pesquisas Tecnológicas, atual Tecpar (PASSOS, 1998). Já no âmbito do 4o período de Dahlman \& Frischtak (1993) instalaram-se outras unidades de pesquisa no Estado, dentro de uma perspectiva de desenvolvimento de um SNI, uma vez que se trata de instituições pertencentes ao Ministério da Agricultura e à Secretaria Estadual de Agricultura, num contexto de integração agricultura-indústria.

Mais recentemente, no final da década passada, uma nova onda de investimentos industriais ocorreu no Estado. Implantaram-se empresas da indústria automobilística e eletroeletrônica e muitos de seus fornecedores. Pelo volume de investimentos realizados, é possível afirmar que, desse modo, sucedeu-se mais uma onda de alterações na dinâmica econômica do Estado em direção à transformação de seu perfil, de agroindustrial para industrial.

Junto com os novos investimentos surgem outros que decorrem da nova forma de evolução da estrutura da indústria e do mercado, do aumento da disponibilidade de capital humano e da crescente urbanização, em função do fortalecimento de um novo paradigma tecnológico. A consolidação e a difusão dos computadores pessoais e o advento da Internet são importantes fatos que marcaram o momento vivido pelo mundo a partir de meados da década de 1990. Nesse ambiente surge no Paraná, dentro desse movimento de expansão industrial recente, o CITS, empreendimento inerente à nova dinâmica tecnológica. A referência, nesse caso, é a produção de software e a tecnologia da informação (TI) como um todo.

\section{O Software como Fundamento da Mudança Tecnológica}

O software é o próprio novo paradigma tecnológico em função de que concentra a matéria-prima básica, que é o conhecimento. Esse novo paradigma caracteriza-se por um agrupamento de inovações técnicas, organizacionais e administrativas inter-relacionadas que resul- tam numa nova gama de produtos e de sistemas, mas também, sobretudo, por uma nova dinâmica da estrutura dos custos relativos de todos os insumos para a produção. Antes, a dinâmica econômica tinha como fundação insumos energéticos de baixo custo, excesso de trabalho não-qualificado e tecnologias eletromecânicas. Já neste novo paradigma a dinâmica é dada predominantemente pela interação entre as variáveis: alta qualificação do trabalho e insumos informacionais de baixo custo, derivados do avanço da tecnologia microeletrônica e das telecomunicações (CASTELLS, 2000).

Um elemento fundamental para a aquisição desses conhecimentos mais complexos é a formação de rede de instituições (firmas, universidades, institutos de pesquisas) que permite a conjugação, de forma dinâmica, das diversas competências, para a melhoria da capacidade inovativa e de aquisição de conhecimentos. As redes não só viabilizam o intercâmbio das competências entre os seus agentes, mas, também, por interação e cumulatividade, agilizam a produção de novos conhecimentos. Dado que muitos desses conhecimentos se materializam na difusão das TIs, é possível gerar um grande volume de informações, em função de que cada comando ou decisão tomada ao nível das TIs é registrado e, portanto, quantificável. O grande desafio é exatamente saber como transformar essas informações em conhecimento. É nesse ponto que a qualificação assume papel chave.

\section{As Perspectivas para o Desenvolvimento a partir das Tls}

Segundo a United Nation Commission on Science and Technology for Development (UNCSTD), citada por Mansell \& When (1998), há um reconhecimento generalizado do papel revolucionário que o conhecimento e as TIs podem ter para o desenvolvimento global. Entretanto, os esforços necessários para a sua mais rápida difusão parecem que não estão sendo suficientes; os formuladores de política e organismos internacionais ainda não conseguiram criar condições de se alcançar uma verdadeira infra-estrutura global de informação. Considerando essas incapacidades, segundo a Commission (MANSELL \& WHEN, 1998) haveria quatro grupos de países divididos pelo grau de difusão interno das TIs: países com ampla difusão; países com a difusão em alguns setores; países com rara difusão; e países totalmente excluídos da sociedade de informação.

Para romper essa situação seria necessário seguir algumas recomendações dadas pela Commission (MANSELL \& WHEN, 1998). Os países em desenvolvimento devem:

1. Criar uma estratégia nacional de TIs por meio da constituição de instituições técnicas, econômicas e sociais que favoreçam o seu uso e disseminação; 
2. Priorizar as políticas de regulação, educação e treinamento voltadas ao estímulo criativo de produção e uso das TIs; e

3. Buscar diversos tipos de arranjos cooperativos de diversas naturezas para esta prioridade. Trata-se de buscar arranjos entre governos, entre governo e setores privados e dos setores privados entre si.

Em termos mais amplos, é necessário buscar uma combinação criativa entre competências científica, tecnológica e gerencial e direcioná-las para a produção e uso de TIs que respondam mais rapidamente aos objetivos de desenvolvimento. Trata-se de uma estratégia nacional de TIs que implica o estabelecimento de uma ampla economia de rede nos moldes TH III.

\section{As Tls no Brasil}

A primeira estratégia nacional relacionada às TIs no Brasil remonta aos anos 1970 e 1980 e, basicamente, refere-se a uma política industrial de reserva de mercado que visava à proteção da indústria nacional de hardware. Com a reserva de mercado acreditava-se que a indústria nacional tornar-se-ia inovadora. O objetivo era estabelecer limites à importação. Segundo a SOFTEX (2002), essa política alcançou algum resultado positivo. Ao final dos anos 1980 havia no país um conjunto diversificado de empresas de capital nacional na indústria de informática. A produção local cresceu de menos de US\$ 200 milhões em 1979 para mais de US\$ 4 bilhões em 1990. Apesar desse crescimento, a indústria não alcançou a mesma dinâmica desse mesmo mercado no exterior.

Pelo exposto até aqui, é possível perceber que as bases iniciais do SNI no Brasil, mesmo ainda a partir dos anos 1980, quando se inicia o novo paradigma tecnológico, se constroem dentro de uma perspectiva da TH I. Entretanto, nos anos 1990 as condições institucionais globais implicaram a abertura dos mercados brasileiros. Dada a pressão dos países, que apresentavam uma grande oferta de produtos e serviços já consolidada, sobre o Brasil para a liberalização, diversos segmentos da economia brasileira desregulamentaram seus mercados e foram rapidamente expostos à competição externa. Uma ampla reestruturação ocorreu em diversos segmentos da indústria.

$\mathrm{Na}$ perspectiva da política científica e tecnológica, foram essas condições mais gerais que determinaram o recuo do papel do Estado como agente determinante da construção do SNI e, conseqüentemente, da mudança na forma de interação entre as helix em direção à concepção TH II. O importante a se destacar é que esse recuo do Estado não implicou em estabilizar a organização do SNI numa situação relativamente menos propícia à inovação. Diversas ações de políticas tecnológicas foram implementadas, porém, já numa perspectiva liberalizante à la TH II. Na indústria de informática o reflexo desse movimento de natureza política resultou na implementação da Lei 8248/91 (Lei de Informática) que tinha como objetivo estabelecer mecanismos de fomento à produção local e às atividades de $\mathrm{P} \& \mathrm{D}$ nessa indústria. As empresas produtoras de bens de informática teriam isenção de impostos se houvesse comprometimento na produção local e de desenvolvimento de atividades de P\&D. De 1993 a 2001, a Lei beneficiou 428 empresas e gerou recursos para $\mathrm{P} \& \mathrm{D}$ da ordem de $\mathrm{R} \$ 2,9$ bilhões no período, sendo $63 \%$ aplicados em pesquisa privada e $33 \%$ em convênios com instituições de pesquisas. Fundamentalmente, esses incentivos beneficiaram mais as empresas de hardware, em especial as multinacionais, do que de software. Entretanto, na medida da abertura do mercado, mesmo com os incentivos, a indústria nacional já não conseguia competir em pé de igualdade com o exterior. A Lei como mecanismo de incentivo veio tarde demais, não sendo suficiente para permitir ganhos de competitividade da indústria nacional (SOFTEX, 2002).

Um outro instrumento de política de informática usado no início dos anos 1990 foram o Projeto de Desenvolvimento Estratégico da Informática (DESI), criado pelo CNPq, e o Programa das Nações Unidas para o Desenvolvimento (PNUD). Dentro do Projeto, no que se refere ao desenvolvimento de software, havia o Programa Nacional de Software para Exportação. Até 2002, o Programa havia montado uma rede de agentes em 22 cidades (o CITS foi o primeiro agente) e criado uma linha de financiamento, em parceria com o BNDES, para empresas de software (PROSOFT). As empresas associadas ao Programa representavam 37\% do total de empresas de software no País. O objetivo do programa era aumentar a desconcentração regional, a capacitação na gestão empresarial, a taxa de inovação de processos e produtos e a adequação ao mercado (SOFTEX, 2002). Mais recentemente, as ações de política pública relacionada com o tema foram: o lançamento de novos mecanismos e fontes de investimentos em pesquisa científica e tecnológica, como os Fundos Setoriais; a realização da Conferência Nacional de Ciência, Tecnologia e Inovação; a renovação da Lei de Informática; e a elaboração de uma Lei de Inovação (LORENZI, 2003).

É possível destacar que essas ações decorrem de uma evolução para a TH III, uma vez que elas ressaltam o caráter cooperado entre os agentes, ao mesmo tempo em que buscam estimular uma postura mais ativa por parte das firmas. A Lei de Informática, por exemplo, oferece incentivos fiscais às empresas que invistam em $\mathrm{P} \& \mathrm{D}$, internamente e através de convênios com universidades e institutos de pesquisa. Ao longo do tempo, a atual lei 
pode ser considerada a terceira Lei de Informática. A primeira vigorou de 1984 a 1991 e tinha como política fundamental à proteção de mercado. A segunda, vigente de 1992 a outubro de 2000, tinha como foco a diversificação no número de firmas da área de TI. E a atual lei dá mais ênfase à $P \& D$ no sentido de melhorar a sua desconcentração regional, por meio da obrigatoriedade das empresas investirem em outras regiões menos desenvolvidas não localizadas nas regiões Sul e Sudeste do Brasil. Em termos dos benefícios fiscais se estabeleceu uma determinada progressividade de total eliminação em 2019. Ademais, as empresas passam a ter a obrigação de investir por linha de produtos incentivados, e não mais com base em seu faturamento bruto total. Essa nova dinâmica permite a todos os agentes otimizar os resultados obtidos em termos tecnológicos e, fundamentalmente, em termos econômico-financeiros. Outro exemplo é a Lei de Inovação, que estabelece medidas de incentivo à pesquisa e à inovação e cria mecanismos de gestão, para as instituições de ensino e $\mathrm{P} \& \mathrm{D}$, no que diz respeito à relação com as empresas, principalmente, de base tecnológica.

O CITS foi o primeiro agente do Programa SOFTEX. Assim, em função de já ter passado por diversas fases no seu desenvolvimento, e considerando as mudanças tecnológicas e do ambiente econômico-institucional das décadas de 1980 e 1990, pretende-se a partir daqui discutir a sua trajetória tecnológica e a aquisição de competências.

\section{A Evolução do CITS}

A forma como o CITS foi concebido e se desenvolveu demonstra o processo interativo entre as helix. Trata-se de uma entidade civil de direito privado, sem finalidade lucrativa, localizada em um aglomerado de firmas de TI, o Parque de Software de Curitiba. O CITS foi criado em junho de 1992, como resultado de uma ação cooperada proposta pelos setores empresarial e acadêmico do setor de software e com o apoio dos governos municipal e estadual. É fundamental destacar que participam de sua gestão os três elementos da $\mathrm{TH}$, com paridade no direito de voto.

Inicialmente, o CITS possuía cerca de 20 associados mantenedores e a trajetória de evolução permitiu chegar, atualmente, ao número aproximado de 50, que são originários dos diversos segmentos da economia que se relacionam de alguma forma com as TIs. São pequenas, médias e grandes empresas, públicas e privadas; instituições de ensino público (municipal, estadual e federal) e privadas. Cabe ressaltar que o Conselho de Administração do CITS é composto por nove membros, três de cada um dos segmentos representados: empresas representantes da iniciativa privada, empresas públicas e universidades e instituições de ensino. Esta composição, onde cada helix possui o mesmo número de representantes das demais, permite uma gestão mais equilibrada, permitindo que todos os atores tenham, em princípio, o mesmo nível de contribuição e envolvimento.

\section{ao reduzir sua importante atuação, privatizou ativos estatais da infra-estrutura, chaves do desenvolvimento econômico brasileiro}

É importante ressaltar que nesses processos iniciais de concretização de uma nova idéia existe um componente de natureza subjetiva, porém relevante, que explica, em parte, a conjugação de interesses dos capitais em torno da inovação. A dinâmica das instituições e a mudança, em parte, se explicam pelo caráter schumpeteriano do empresariado mantenedor, que dentro do processo de acumulação entende a necessidade de ser o first-mover. Nesse sentido, a idéia da constituição do CITS - mesmo que estimulado por uma política pública de natureza macro, o SOFTEX - não teria sido viabilizada se os mantenedores iniciais não tivessem a visão política de perceber que em Curitiba havia um ambiente seletivo propício, em termos de capacitação e estrutura industrial, e, conseqüentemente, um bom potencial de mercado. Se a disponibilidade efetiva dessas condições era discutível, pelo menos significa dizer que o empresariado local mostrava a disposição de se mobilizar em torno de um empreendimento totalmente novo, porém, basal da mudança de paradigma tecnoeconômico. Essa disposição fica evidente nessa citação da ata da assembléia geral de constituição da entidade: Somente a soma de esforços em pesquisa tecnológica e em formação de pessoal poderá resultar no desenvolvimento tecnológico do nosso Estado [...] (CITS, 1992:2).

\section{Trajetória Tecnológica e os Níveis Micro, Meso e Macro}

Após o entendimento das razões da constituição do CITS é necessário entender a sua evolução até os dias atuais e as implicações acarretadas em termos da sua 
trajetória tecnológica. Nesse aspecto, busca-se aqui entender o processo de formação de uma rede de conhecimentos e aquisição de competências ou do conhecimento nas categorias de Lundvall \& Johnson (1994): Knowwhat, conhecimento a respeito dos fatos; Know-why, conhecimento a respeito dos princípios e leis de movimento da natureza, da mente humana e da sociedade; Know-how, habilidades de fazer algo; e Know-who, envolve informação a respeito de que knows-what e who knows-what (rede de conhecimentos). Para esse objetivo serão usados aqui os três níveis de análise do SNI de Cimoli \& Della Giusta (1999), já expostos na Introdução.

\section{Uma Análise do CITS em Nível Micro}

O início da vida do CITS foi marcado por uma atividade mais de natureza administrativa do que propriamente de desenvolvimento de software. Por conta da limitação do espaço físico, da falta de profissionais devidamente capacitados e de recursos financeiros suficientes, o CITS atuou mais como gestor de contratos do que de projetos de desenvolvimento, ou seja, para as demandas iniciais, o CITS subcontratava parte do conhecimento necessário para o desenvolvimento dos projetos propostos ${ }^{3}$. Parte dos projetos era desenvolvida fora da entidade ou pelo menos por capacitação externa ao CITS.

Nessa fase inicial, o primeiro grande contrato da entidade ocorreu com a empresa Siemens, cujo objeto era o desenvolvimento de sistemas de software relacionados a telecomunicações. O que muito contribuiu para a efetivação desse contrato foi a Lei de Informática na sua segunda versão, que obrigava (e ainda obriga) determinadas empresas a investirem um percentual gradual de seu faturamento em P\&D fora da firma. Desse modo, uma vez que, o CITS ainda não detinha todo o conhecimento necessário, a gestão e a responsabilidade dos projetos eram exclusivas da firma. Em última instância, o CITS atuava como um gestor de contratos de atividades de desenvolvimento e abrigo formal, em função de uma obrigação legal. Nesse sentido, apesar da legalidade do processo, o conhecimento adquirido pelo pessoal contratado não criava externalidades para o próprio CITS, pois esse pessoal trabalha numa atividade exclusiva da Siemens. Pode-se dizer que, nessa fase, o nível de conhecimento limitava-se a alguma intuição sobre o knowwhat. A importância da Siemens neste período inicial se relaciona à aquisição de competências para processos de gestão, tanto de caráter administrativo como de caráter tecnológico. Este relacionamento inicial permitiu que as competências fundamentais dos profissionais da instituição fossem gradativamente construídas de acordo com as áreas de interesses mútuos (Siemens/CITS). Em outras palavras, tanto competências específicas na área de tele- comunicações, como competências na área de processos de desenvolvimento e gestão de projeto de alta complexidade tecnológica foram importantes para formar um conceito da instituição no mercado. A alta complexidade dos projetos, obviamente implicando elevados riscos, determinava ações graduais na utilização de processos de reconhecida eficácia.

O início do relacionamento com a Hewlett-Packard (HP) permitiu a mudança de trajetória de gestão da entidade. A partir desse momento, o CITS mudou o foco de atuação como gestor de contrato para gestor de projeto. A natureza do interesse da firma era diferente do da Siemens. Seu interesse foi o de contratar a entidade para que desenvolvesse módulos de software que se acoplariam a outros sistemas. Ela buscava o desenvolvimento de sistemas complexos na linha de produtos específicos (impressoras de jato de tinta) a partir de uma metodologia de desenvolvimento de sistemas baseada nos conceitos de engenharia de software. Nesse sentido, a empresa pretendia atribuir ao CITS a responsabilidade plena do desenvolvimento do projeto em função do seu grau de autonomia e competência. Na medida em que a entidade adquiria autonomia financeira, em função dos projetos conduzidos junto a outras empresas pelo modelo de gestão de contratos, foi possível iniciar a contratação e treinamento de pessoal para a aquisição das competências necessárias ao desenvolvimento das demandas da HP. A HP teve um papel relevante na medida em que contribuiu para a evolução no processo de aquisição de novos conhecimentos da entidade e atribuição gradual de responsabilidades. Ou seja, a HP não atuou apenas numa relação cliente-fornecedor, mas numa troca de ativos complementares (conhecimento por experiência em engenharia de software).

Simultaneamente ao início do relacionamento com a HP, dois profissionais do CITS encontravam-se em processo de capacitação na área de processos de desenvolvimento de software, com foco no aspecto da qualidade, no Software Engeneering Institute, na Carnegie Mellon University, EUA. Isso permitiu um salto qualitativo em termos de capacidade de responder às demandas do mercado e, ao mesmo tempo, difundir esse conhecimento a outras firmas de TIs. A partir desse momento, foi possível contratar e manter uma série de profissionais nas mais diferentes áreas da engenharia de software e, portanto, internalizar efetivamente uma área de desenvolvimento.

$\mathrm{O}$ relacionamento com a HP e a capacitação levaram a uma mudança qualitativa no volume de conhecimentos adquiridos. De uma limitada capacidade de know-what foi possível passar para um conhecimento know-why e, na sequiência imediata, de know-how, ou seja, aprendia-se e ao mesmo tempo executavam-se projetos de desenvolvimento. 
Como é possível notar, mesmo ao nível desse corte de análise, a consolidação do CITS implicou a construção de relacionamentos iniciais sólidos que permitiram a sustentação financeira e a evolução no processo de aquisição de competências. Significa dizer que a formação de um tipo de rede faz parte da natureza desse tipo de instituição, dado que o conhecimento necessário para essa atividade não é facilmente transferível e só se adquire coletivamente. Portanto, a dinâmica da evolução das atividades desse tipo de instituição só pode ser entendida, também, a partir de uma perspectiva mesoeconômica.

\section{Uma Análise do CITS em Nivel Meso}

Mais recentemente, já com uma experiência elevada, conhecimentos consolidados e em processo contínuo de evolução, a instituição passou a atuar junto às firmas que não têm a obrigatoriedade de investir em instituições de $\mathrm{P} \& \mathrm{D}$, como contrapartida aos incentivos fiscais. Por conta de todo um processo de prospecção de mercado e de aspectos de negócios, o CITS obteve dois contratos relevantes do ponto de vista do volume financeiro e de externalidades relacionadas à aquisição de novos conhecimentos (knowwhy e know-how) em ferramentas de software. São contratos com firmas inovadoras da indústria aeronáutica. Mais especificamente, a EMBRAER e a TAM Linhas Aéreas. A evolução atual dos conhecimentos adquiridos permitiu ao CITS, no caso da EMBRAER, desenvolver uma ferramenta de integração de diversas outras ferramentas de apoio ao projeto e à construção de aeronaves. No caso da TAM, o CITS estabeleceu os requisitos

básicos para o desenvolvimento de um sistema de manutenção de aeronaves, dentro de avançadas técnicas de logística existentes.

Um outro contrato relevante nesse processo de aquisição de conhecimento foi o realizado com o Governo do Paraná e teve como objetivo a elaboração do sistema de gestão previdenciária do Estado. A partir do governo passado, com a reforma do serviço previdenciário estadual (antigo IPE), foi necessário reformular todos os processos e, conseqüentemente, abriu-se espaço para uma intensificação do uso de TI nesse serviço. Nisso, o CITS esteve envolvido por mais de três meses, estudando os fluxos e processos e sugerindo novas rotinas. $\mathrm{Na}$ seqüência, elaborou o sistema num processo interativo e modular cuja finalização totalizou quase dois anos. Nesta mesma linha de atuação, recentemente o CITS iniciou o desenvolvimento de um projeto para o Governo do Estado do Mato Grosso ${ }^{4}$.
Trata-se de um negócio possível exatamente em função da crescente rede de parceiros construída ao longo dos tempos pela instituição. Nesse processo estão envolvidos associados ao CITS como também parceiros de associados. Em outros termos, trata-se do crescimento da instituição em função dos relacionamentos de rede.

Dessas experiências há que se ressaltar dois ganhos significativos: um é o aprofundamento permanente no aprendizado capaz de chegar a um nível de know-who e a formação de redes, pelo processo de learning-by-interacting e learning-by-using, nas diversas tecnologias de software, além do treinamento formal. Isso decorre do fato de que todas as soluções de sistemas propostos são customizadas, ou seja, o objetivo do CITS não é desenvolver pacotes para comercialização nos canais tradicionais. As relações contratuais devem implicar complexidade tecnológica e, conseqüentemente, mudança qualitativa no aprendizado. O objetivo é buscar uma curva de aprendizado cada vez mais acentuada a cada novo contrato. Com o conhecimento acumulado crescente, o tempo de desenvolvimento de novos sistemas torna-se decrescente. Cumulatividade implica ganho de escala no aprendizado (assimila-se o conhecimento mais rapidamente) e na produção (desenvolvimento de novos sistemas/software).

\section{N esse ambiente surge no Paraná, dentro desse movimento de expansão industrial recente, o CITS, empreendimento inerente à nova dinâmica tecnológica.}

Uma conseqüência dessa cumulatividade é que, ao longo do tempo, o CITS desenvolveu uma rotina de difusão dos conhecimentos técnicos adquiridos por meio de programas de educação continuada. Trata-se de cursos periódicos relacionados às tecnologias de software envolvidas na solução dos problemas, como linguagens de programação, plataformas de desenvolvimento e arquiteturas utilizadas. Eventualmente, essas atividades de educação podem requerer a utilização de pesquisadores externos, oriundos, por exemplo, das universidades, como forma de complementar, do ponto de vista teórico, o conhecimento adquirido na condução dos projetos desenvolvidos.

Considerando essa evolução nos níveis micro e mesoeconômico é possível resumir a trajetória do CITS conforme o Quadro 1. A instituição já foi capaz de internalizar as quatro categorias do conhecimento. A partir do momento que ela consegue difundir conhecimentos, é porque tem pleno domínio de know-what, know-why e 
know-how. O CITS, portanto, já possui know-who. A possibilidade de se avançar para a fase 4 depende, portanto, da evolução das competências, porém, principalmente da capacidade de financiamento. Em outros termos, para as inovações radicais que estejam além do desenvolvimento de soluções (ou melhorias incrementais nos sistemas preexistentes), é necessária a pesquisa e conseqüentemente sua fonte de financiamento.

Quadro 1: Fases da tragetória tecnológica do CITS e suas características.

\begin{tabular}{|c|c|c|c|c|}
\hline FASE & DESCRIÇÃO & $\begin{array}{l}\text { PROGESSOS } \\
\text { TÍPIGOS }\end{array}$ & $\begin{array}{l}\text { ASPECTOS } \\
\text { FAVORÁVEIS }\end{array}$ & $\begin{array}{l}\text { IMPLIGAÇÕES SOBRE A } \\
\text { INOVAÇÃO E O } \\
\text { GOMPORTAMENTO DA TH III }\end{array}$ \\
\hline $\begin{array}{l}1 \\
\text { Competência } \\
\text { Técnica }\end{array}$ & $\begin{array}{l}\text { Fornecimento de } \\
\text { equipamentos e } \\
\text { recursos humanos } \\
\text { coordenados pelo } \\
\text { cliente (ex.: projetos } \\
\text { com core business do } \\
\text { mantenedor]. } \\
\text { Conhecimento: Know- } \\
\text { what }\end{array}$ & $\begin{array}{l}\text { Contratos de } \\
\text { prestação de } \\
\text { contas. }\end{array}$ & $\begin{array}{l}\text { Criação de } \\
\text { infra-estrutura. } \\
\text { Início de novas } \\
\text { competências. } \\
\text { Novos clientes. }\end{array}$ & $\begin{array}{l}\text { Baixo domínio do processo. } \\
\text { Baixíssima interação } \\
\text { com o cliente. } \\
\text { Dependência de política pública. } \\
\text { O estado tem um papel mais } \\
\text { relevante do que os demais } \\
\text { agentes. } \\
\text { Há ainda pouca interação em } \\
\text { direção à hibridização. }\end{array}$ \\
\hline $\begin{array}{l}2 \\
\text { Gestão } \\
\text { Técnica }\end{array}$ & $\begin{array}{l}\text { Coordenação do } \\
\text { projeto desde o } \\
\text { levantamento de } \\
\text { requisitos até o teste. } \\
\text { Conhecimento: Know- } \\
\text { what e know-why }\end{array}$ & $\begin{array}{l}\text { Metodologias } \\
\text { de gestão de } \\
\text { projetos. }\end{array}$ & $\begin{array}{c}\text { Domínio da } \\
\text { competência sobre os } \\
\text { processos. } \\
\text { Incorporação efetiva } \\
\text { dos funcionários. }\end{array}$ & $\begin{array}{l}\text { Especificação trazida pelo } \\
\text { cliente. } \\
\text { Baixa interação com o mercado. } \\
\text { Iniciativa de uma ação mais } \\
\text { pró-ativa e interação com } \\
\text { outros agentes. }\end{array}$ \\
\hline $\begin{array}{c}3 \\
\text { Fornecimento } \\
\text { de Soluções } \\
\text { FASE ATUAL }\end{array}$ & $\begin{array}{l}\text { Busca de novos } \\
\text { mercados e clientes } \\
\text { em projetos complexos, } \\
\text { fornecendo soluções } \\
\text { customizadas. } \\
\text { Pleno conhecimento: } \\
\text { Know-what, know- } \\
\text { why, know-how e } \\
\text { know-who. }\end{array}$ & $\begin{array}{l}\text { Capacidade de } \\
\text { negociação de } \\
\text { contratos e } \\
\text { prospecção de } \\
\text { negócios. }\end{array}$ & $\begin{array}{l}\text { Aproveitamento das } \\
\text { competências e infra- } \\
\text { estrutura existentes. } \\
\text { Conhecimento do } \\
\text { mercado nacional e } \\
\text { internacional. } \\
\text { Possibilidades de } \\
\text { subcontratação de } \\
\text { mantenedores. }\end{array}$ & $\begin{array}{l}\text { Maior complexidade - exige } \\
\text { novas habilidades e controles. } \\
\text { Maior risco e exigência de } \\
\text { eficiência. } \\
\text { Há tentativas de maior } \\
\text { interação com a academia ao } \\
\text { mesmo tempo necessidade de } \\
\text { incorporação de profissionais } \\
\text { mais qualificados (doutores]. }\end{array}$ \\
\hline $\begin{array}{c}4 \\
\text { Produtos } \\
\text { Inovadores }\end{array}$ & $\begin{array}{c}\text { Royalties de } \\
\text { propriedade } \\
\text { intelectual, parcerias } \\
\text { estratégicas, P\&D } \\
\text { em componentes. } \\
\text { Conhecimento: } \\
\text { competência para } \\
\text { inovação radical. }\end{array}$ & $\begin{array}{l}\text { Articulação de } \\
\text { parcerias com } \\
\text { os } \\
\text { mantenedores. } \\
\text { Articulação } \\
\text { entre as áreas } \\
\text { pensando na } \\
\text { gestão de todo } \\
\text { o ciclo de vida } \\
\text { do negócio } \\
\text { inovador. }\end{array}$ & $\begin{array}{l}\text { Retorno decorrente da } \\
\text { propriedade intelectual. } \\
\text { Amplas competências } \\
\text { desenvolvidas. } \\
\text { Competência para } \\
\text { alavancar empresas } \\
\text { locais para o mercado } \\
\text { nacional e internacional. } \\
\text { Parceria na concepção } \\
\text { inovadora do negócio. } \\
\text { Novas oportunidades } \\
\text { de P\&D. } \\
\text { Maior leque de fontes } \\
\text { de financiamento. }\end{array}$ & $\begin{array}{l}\text { Risco crescente - rigor no } \\
\text { planejamento do produto. } \\
\text { Maior complexidade - maiores } \\
\text { habilidades e interatividade } \\
\text { Intensidade do processo } \\
\text { cooperativo entre os atores. } \\
\text { Necessidade de uma rede } \\
\text { melhor organizada de } \\
\text { interações com outras } \\
\text { instituições relacionadas. } \\
\text { Implica plena interação entre } \\
\text { as helix e a efetiva ação } \\
\text { híbrida na concepção TH III. }\end{array}$ \\
\hline
\end{tabular}




\section{Uma Análise do CITS em Nivel Macro}

Do ponto de vista macro, como é de senso comum, a relevância da política industrial que tenha efeitos significativos ainda é modesta quando inserida no contexto da ciência, tecnologia e inovação no Brasil. Muito embora exista uma aproximação operacional junto aos órgãos federais, como a FINEP e o Ministério da Ciência e Tecnologia, o relacionamento em nível estratégico ainda não foi exercido na profundidade necessária para melhorar a posição da instituição em termos de se tornar um centro de referência no desenvolvimento de software, assim como influenciar nas discussões de temas relevantes. Entretanto, é relevante destacar o forte papel que a Lei de Informática teve no início da existência do CITS. Como pôde se notar, ela foi determinante para o início de suas operações e sobrevivência, uma vez que grande parte do faturamento advinha de contratos no âmbito dessa legislação. Algumas firmas mantêm relacionamentos com o CITS em função da legislação, o que acabou colaborando para a evolução da instituição. Isso não significa que somente o faturamento decorrente dessas empresas viabiliza o CITS, mas sim que ele foi e é fundamental para a sua estabilidade.

Do ponto de vista da política pública estadual, a referência possível é ao SLI, pois a evolução cria um ambiente propício às atividades da instituição. Na medida em que as instituições existentes no Estado, tais como o TECPAR, Fundação Araucária, IBQP e as universidades, se fortalecem nas suas diversas atividades-chaves, é lógico afirmar que o ambiente para uma atividade que implica conhecimento e capacidade de inovação se torna mais propício e as relações institucionais entre os agentes do sistema se tornam mais intensas e consolidadas. Porém, do ponto de vista da ação direta, é possível afirmar que não houve ainda uma atuação do estado que pudesse ser relevante na trajetória do CITS.

Por último, vale ressaltar o papel da Prefeitura Municipal, que atuou no início do CITS, por meio da construção da sede do Parque de Software, onde funcionou o CITS até recentemente.

A discussão sobre o papel das instituições no nível macro vai além do que se propõe este artigo. Na verdade, a relevância ou influência do nível macro sobre o CITS relaciona-se à discussão do papel da política industrial, aos seus instrumentos e ao seu âmbito de atuação no sistema de inovação (local e/ou nacional). O nível macro terá papel ativo sobre esse tipo de instituição na medida em que as ações sobre os sistemas de inovação estejam plenamente definidas. Portanto, entender o papel do nível macro implica encontrar elementos claros de política sobre o sistema de inovação como um todo. Essa é uma discussão mais ampla, fora do contexto deste artigo.

\section{CONCLUSÕES}

Este artigo teve como objetivo principal analisar o CITS como instituição híbrida e naturalmente inovadora numa organização institucional nos padrões da TH III. $\mathrm{Na}$ discussão sobre o processo de construção do SNI e, dentro dele, o do SLI, verificou-se que o SLI do Paraná foi construído e atrelado a uma dinâmica de economia agropecuária, em contraposição à construção do SNI, num ambiente de industrialização pesada. Uma dinâmica industrial propriamente dita, no Paraná, só pôde ser vista no Estado a partir dos anos 1970, quando plantas da indústria metalúrgica, mecânica, química e petroquímica se instalaram na Região Metropolitana de Curitiba. Apesar da industrialização, não se pode afirmar que havia indícios de uma gestação de um SLI, uma vez que as ações de $\mathrm{P} \& \mathrm{D}$ eram eventuais.

Em meados da década passada, uma nova onda de investimentos da indústria automobilística, eletroeletrônica e seus fornecedores teve lugar no estado. Uma vez que esses novos investimentos ocorreram dentro de um novo paradigma tecnológico, junto se viabilizaram novos empreendimentos inerentes a essa dinâmica. Mais especificamente, foram investimentos relacionados ao desenvolvimento das TIs que viabilizaram a escala para o surgimento de uma atividade também paradigmática que é a produção de software. Ou seja, a nova onda de industrialização do Estado criou um ambiente propício para se instalar um centro de desenvolvimento de TIs.

Este artigo teve como um dos seus fundamentos a afirmação que o software é a materialização do novo paradigma tecnológico, uma vez que ele concentra a sua matéria-prima básica: o conhecimento. Trata-se de um novo paradigma porque todas as atividades têm suas produtividades determinadas pelas TIs e sua evolução depende da cumulatividade do conhecimento.

Nesse sentido, considerando que o conhecimento é ilimitado, o desafio fundamental para os países é encontrar uma estratégia nacional de TIs. Para isso, é necessário buscar os mais diversos tipos de arranjos institucionais: entre governos, entre governo e setores privados e entre setores privados. Os governos têm o papel central na viabilização e formação desses arranjos e o CITS aparece como uma estratégia acertada decorrente dos esforços institucionais locais.

As diversas versões da Lei de Informática nos 70/80 significaram uma sinalização nessa direção. Com elas foi possível o desenvolvimento de uma indústria de informática, centrado no desenvolvimento de hardware, porém, pouco competitiva em função da reserva de mercado, que foi a característica central das primeiras fases da Lei. Num novo ambiente de abertura dos mercados dos 
anos 1990 a $3^{a}$ fase da Lei prioriza mais a criação de competências seletivas no desenvolvimento de software do que aspectos hard como foi no passado. O instrumento nessa perspectiva é o Projeto de Desenvolvimento Estratégico da Informática. Dentro dele estava o Programa Nacional de Software para Exportação (Programa SOFTEX). O primeiro agente desse Programa foi o CITS.

Numa primeira fase, o CITS atuava como gestor de contratos, não possuindo autonomia e competência para o desenvolvimento de software. Atuava como instituição determinada pelos clientes. O grau de conhecimento se restringe a uma noção de Know-what. Na segunda fase, há um aumento da competência técnica por conta dos diversos projetos realizados, porém, ainda com um grau de autonomia reduzido. O conhecimento é fundamentalmente detido pelo cliente. $\mathrm{O}$ conhecimento detido pela instituição se aprofunda e incorpora o Know-why. Na terceira fase, aumenta significativamente o conhecimento adquirido e conseqüentemente a autonomia. Há pleno conhecimento do estado-da-arte. Os aspectos técnicos do know-how e do know-who, somente são estabelecidos internamente nessa fase. No caso do CITS, a mudança das fases foi fundamentalmente determinada pelo relacionamento com a HP. O atual desafio do CITS é passar para a quarta fase que, por tratar-se de pesquisa e, portanto, com implicações em gastos não-reembolsáveis, depende de fontes de financiamento que possam surgir dos próprios arranjos institucionais público/privado. Se for possível alcançar essa quarta etapa, o CITS tem plenas condições de inovar efetivamente, numa perspectiva radical. A situação atual é de um direcionamento para a inovação radical após ter passado por fases de inovação incremental. Portanto, o CITS ainda não pode ser considerado uma instituição completa com ações híbridas à la TH III, mas, por conta da forma em que foi concebido e desenvolveu-se, o ambiente em que convive e as determinações de políticas públicas, tende alcançar esse tipo de dinâmica inovativa.

Nota-se, portanto, em resposta à primeira questão (seção Metodologia da Pesquisa); que o conhecimento que tem caráter coletivo e se relaciona à capacidade cognitiva das organizações e indivíduos só pode ser adquirido ao longo de uma trajetória intertemporal construída a partir de estratégias tecnológicas que tinham implícita a necessidade de ambiente adequado para se formar uma rede econômica entre instituições nos níveis micro, meso e macro.

Ficou claro - em atenção à segunda questão - que é necessário mais foco nesse tipo de instituição, uma vez que trata-se de um elemento novo que se insere numa reorganização do SNI, buscando agregar competências tecnológicas a partir da helix indústria, o que não era tradicional no Brasil, ao mesmo tempo em que se trata de geração de valor a partir do software, que é um dos elementos mais importantes do atual paradigma tecnológico. Pensar minimamente numa política de software (política vertical), pela sua relevância e possibilidades de externalidades, já seria atacar forte e seletivamente a ausência de uma política industrial horizontal.

Por último, resgatando a terceira questão, arrisca-se aqui algumas eventuais proposições de política que tenham em consideração a busca de ações híbridas numa perspectiva TH III.

$\checkmark$ Acelerar a oferta de profissionais de elevada titulação (mestrado e doutorado) por meio de convênios específicos com a UFPR e CEFET nas áreas tecnológicas. Essas duas instituições podem incorporar à sua pós-graduação acadêmica a modalidade de Mestrado Profissionalizante prevista pela CAPES, que pode ser bem direcionada aos interesses do SLI.

$\checkmark$ Essa atuação mais forte das universidades na TH no âmbito da pós-graduação stricto sensu implicaria alta coordenação que necessariamente somente poderia ser assumida pelos governos municipal e estadual, uma vez que se trata de ações para a expansão do SLI.

$\checkmark$ Aumentar o volume de recursos voltados à inovação, assim como à realização de acordos de cooperação do tipo alianças estratégicas com instituições federais e empresas nacionais e do exterior. Acordos de cooperação dessa natureza são importantes porque, como se ressaltou no texto, o gargalo atual do CITS para evoluir é a incapacidade (de qualificação como de recursos a fundo perdido para $\mathrm{P} \& \mathrm{D})$ de adquirir novos conhecimentos.

$\checkmark$ Mais uma vez, os governos assumem papel fundamental porque devem promover e coordenar a aproximação entre as instituições privada-pública, pública-pública e privada-privada. O Estado tem amplas condições de criar rapidamente mecanismos de prospecção e vigilância buscando agentes disponíveis e interessantes para a formação de alianças estratégicas;

$\checkmark$ Instituições de suporte à pesquisa como a Fundação Araucária podem assumir um papel-chave de apoio e coordenação dessas estratégias;

$\checkmark$ Por último, vale ressaltar que, na verdade, a definição das diversas ações de política a serem implementadas não é tarefa exclusiva do pesquisador, e sim este deve atuar mais como sintetizador e organizador da hibridização da TH. Em outros termos, não se trata de impor determinadas ações ao SLI a partir do Estado, mas este deve criar mecanismos de aglutinar os seus diversos agentes em torno de uma mesa de negociações, de tal forma que eles próprios sejam os definidores das suas necessidades e estratégias. Em termos aplicados, quaisquer eventuais ações de política de inovação devem ser precedidas da criação de fóruns e de uma ampla mobilização e discussão da TH III. 


\section{Artigo recebido em 15/06/2005 Aprovado para publicação em 21/10/2005}

\author{
- Notas \\ 1. O Centro Internacional de Tec- \\ nologia de Software localiza-se em \\ Curitiba, no Paraná. \\ 2. Em SHIMA (2004) é discutido o \\ efeito desse suposto quinto perío-
}

\begin{abstract}
3. Na verdade, dado o varejo das poucas demandas iniciais, as competências demandadas pelo mercado eram, e ainda são, diversas e nessa fase seria impossível que todo o conhecimento estivesse concentrado em poucos profissionais. Embora o CITS tivesse em seu quadro de pessoal profissionais com competências
\end{abstract}

específicas em determinados campos das TIs, estas, não necessariamente, cobriam toda a gama demandada pelo mercado.

4. Não é um projeto relacionado à previdência do Estado mas sim relacionado à organização da gestão das finanças estaduais.

\section{- Referências Bibliográficas}

CASTELLS, M. A era da informação: economia, sociedade e cultura. (Volume I: A sociedade em rede). 3a edição. São Paulo: Paz e Terra, 2000, 617 p.

CENTRO INTERNACIONAL DE TEC NOLOGIA DE SOFTWARE. Estatuto social. Curitiba, 1992. 25 p.

CiMOLI, M. \& DELla GiUSTA, M. The nature of technological change and its main implications on national and local systems of innovation. Luxenburg, Austria: International Institute for Applied Systems Analysis - IIASA, IR98-029/June.

DAHLMAN, C. J.; FRISCHTAK, C. National system supporting technical advance in industry: the brazilian experience. In: NELSON, R. (ed.). National innovation system: a comparative analysis. Oxford: NewYork, 1993. cap. 13 , p. $414-450$.
DOSI, G. Technological paradigms and technological trajectories. Research Policy, Amsterdam, v.11, Issue 3, p. 147-162, junho/1982.

ETZKOWITZ, H.; BRISOLLA, S. N. Failure and Success: The Fate of Industrial Policy in Latin America and South East Asia. Research Policy, Amsterdam, v. 28, Issue 4, p. 337 350, abril/1999.

ETZKOWITZ, H.; LEYDESDORFF. L. The Dynamics of Innovation: From National Systems and "Mode 2" to a Triple Helix of University-IndustryGovernment Relations. Research Policy, Amsterdam, v. 29, Issue 2, p. 109-123, fevereiro/2000.

LACERDA, A. C.; REIS, D. R.; PERINI, F. A B. Tecnologia: estratégia para a competitividade. $1^{\mathrm{a}}$ edição. São Paulo: Nobel, 2001, 173 p.
LORENZI, A. G. A. A gestão de um instituto privado de pesquisa na dinâmica da inovação no Brasil: caso Cits. 2003. 152 p. Dissertação (Mestrado em Tecnologia) - Programa de Pós-graduação em Tecnologia, CEFET/PR, Curitiba.

LUNDVALL, B.-Å.; JOHNSON, B. The Learning Economy. Journal of Industry Studies, Sydney, v. 1, p. 23-42, 1994.

MANSELL, R. \& WEHN, U. Knowledge society: information technology for sustainable development. 1 a edição. New York: United Nations/Oxford, 1998, 200 p.

OECD. National innovation systems. Paris, $1997,49 \mathrm{p}$

PASSOS, C. A. K.. Sistemas locais de inovação: o caso do Paraná. In: CASSIOLATO, J. E. \& LASTRES, H. M M. (ed.). Globalização e inovação localizada: experiências de sistemas locais no Mercosul, MCT/CNPq/IBICT: Brasília, 1999. cap. 13, p. 335-372.
PERINI, F. A. DE B. Gestão estratégica de tecnologia e inovação em filial de empresa multinacional diversificada: o caso Siemens. 2002. 134 p. Dissertação (Mestrado em Tecnologia) - Programa de Pós-graduação em Tecnologia, CEFET/PR, Curitiba.

SHIMA, WALTER TADAHIRO. The implications of privatization for innovation in Brazilian telecommunications. International Journal of Technology Management and Sustainable Development. Glascow, v. 3. Issue 1, p. 3-16, janeiro/2004

SOFTEX. A indústria de software no Brasil 2002 - fortalecendo a economia do conhecimento - Projeto do Massachussets Institute of Technology. Campinas, 2002, 80 p.

\section{- Sobre os autores}

\section{Walter Tadahiro Shimajv}

Professor Adjunto do Programa de Pós-graduação em Desenvolvimento

Econômico da Universidade Federal do Paraná. Doutor pelo IE/UFRJ (1999).

Endereço: Avenida Lothário Meissner, 3400 - Jardim Botânico - Curitiba - Paraná - Brasil - 80210-170

Telefone: (41) 3360-4469 / 3342-8897 / 8416-6268.

E-mail: waltershima@ufpr.br

\section{Antonio Guilherme de Arruda Lorenzi}

Coordenador Executivo do CITS, Engenheiro de Aeronáutica pelo ITA (1982) e

Mestre em Tecnologia pelo Programa de Pós-graduação em Tecnologia do CEFET/PR (2003).

Endereço: Rua do Semeador, 702 - Parque de Software - Cidade Industrial - Curitiba - Paraná - Brasil - 80270-050

Telefone: (41) 3025-9651 / 9183-3274 / Fax: (41) 3337-1002

E-mail: guilherme.lorenzi@ cits.br 